\section{RON kinase inhibition reduces renal endothelial injury in sickle cell disease mice}

\author{
Alfia Khaibullina, ${ }^{1}$ Elena A. Adjei, ${ }^{1,2}$ Nowah Afangbedji, ${ }^{1}$ Andrey Ivanov, ${ }^{1}$ \\ Namita Kumari, ${ }^{1}$ Luis E.F. Almeida, ${ }^{3}$ Zenaide M.N. Quezado, ${ }^{3}$ Sergei Nekhai ${ }^{1,4,5}$ \\ and Marina Jerebtsova ${ }^{5}$
}

${ }^{1}$ Center for Sickle Cell Disease, College of Medicine, Howard University, Washington, DC; ${ }^{2}$ Departments of Genetics and Human Genetics, College of Medicine, Howard University, Washington, DC; ${ }^{3}$ Department of Perioperative Medicine, NIH Clinical Center, National Institutes of Health, Bethesda, MD; ${ }^{4}$ Department of Medicine, College of Medicine, Howard University, Washington, DC and ${ }^{5}$ Department of Microbiology, College of Medicine, Howard University, Washington, DC, USA

\section{ABSTRACT}

S ickle cell disease patients are at increased risk of developing a chronic kidney disease. Endothelial dysfunction and inflammation associated with hemolysis lead to vasculopathy and contribute to the development of renal disease. Here we used a Townes sickle cell disease mouse model to examine renal endothelial injury. Renal disease in Townes mice was associated with glomerular hypertrophy, capillary dilation and congestion, and significant endothelial injury. We also detected substantial renal macrophage infiltration, and accumulation of macrophage stimulating protein 1 in glomerular capillary. Treatment of human cultured macrophages with hemin or red blood cell lysates significantly increased expression of macrophage membrane-associated protease that might cleave and activate circulating macrophage stimulating protein 1 precursor. Macrophage stimulating protein 1 binds to and activates RON kinase, a cell surface receptor tyrosine kinase. In cultured human renal glomerular endothelial cells, macrophage stimulating protein 1 induced RON downstream signaling, resulting in increased phosphorylation of ERK and AKT kinases, expression of Von Willebrand factor, increased cell motility, and re-organization of F-actin. Specificity of macrophage stimulating protein 1 function was confirmed by treatment with RON kinase inhibitor BMS-777607 that significantly reduced downstream signaling. Moreover, treatment of sickle cell mice with BMS-777607 significantly reduced glomerular hypertrophy, capillary dilation and congestion, and endothelial injury. Taken together, our findings demonstrated that $\mathrm{RON}$ kinase is involved in the induction of renal endothelial injury in sickle cell mice. Inhibition of RON kinase activation may provide a novel approach for prevention of the development of renal disease in sickle cell disease.

\section{Introduction}

Sickle cell disease (SCD) is the most commonly inherited hematologic disorder caused by a single nucleotide mutation in the $\beta$-globin gene (HBB) resulting in $\mathrm{HbS}$ hemoglobin. HbS polymerization leads to sickling and hemolysis of red blood cells (RBCs), vaso-occlusion and organ damage. SCD patients are at increased risk of developing chronic kidney disease (CKD) ${ }^{1,2}$ Renal involvement in SCD can be present in childhood, as evidenced in $16-28 \%$ of children with clinical manifestations of proteinuria and microalbuminuria. ${ }^{3}$ Albuminuria and proteinuria are observed in more than $50 \%$ of adult SCD patients, and renal failure is developed in about $30 \% .4,5$ SCD-associated nephropathy is characterized by tubular dysfunction, which is manifested by inability to concentrate urine, and consequent hyposthenuria and polyuria, and glomerular damage. Glomerular abnormalities are characterized by glomerular hypertrophy, expansion of mesangium, thrombotic
Haematologica 2018

Volume 103(5):787-798

\section{Correspondence:}

marina.jerebtsova@howard.edu

Received: September 15, 2017.

Accepted: March 1, 2018.

Pre-published: March 8, 2018.

doi:10.3324/haematol.2017.180992

Check the online version for the most updated information on this article, online supplements, and information on authorship \& disclosures: www.haematologica.org/content/103/5/787

\section{(C)2018 Ferrata Storti Foundation}

Material published in Haematologica is covered by copyright. All rights are reserved to the Ferrata Storti Foundation. Use of published material is allowed under the following terms and conditions:

https://creativecommons.org/licenses/by-nc/4.0/legalcode. Copies of published material are allowed for personal or internal use. Sharing published material for non-commercial purposes is subject to the following conditions:

https://creativecommons.org/licenses/by-nc/4.0/legalcode, sect. 3. Reproducing and sharing published material for commercial purposes is not allowed without permission in writing from the publisher. 
microangiopathy, focal segmental glomerulosclerosis (FSGS), membranoproliferative glomerulonephritis, and albuminuria..$^{5-8}$ Two major disease mechanisms of chronic kidney disease in SCD have been proposed: 1) hemolysisendothelial dysfunction leading to vasculopathy; and 2) inflammation and hyper-viscosity leading to vaso-occlusion. ${ }^{9}$ Intrarenal RBC hemolysis was suggested to be a trigger for both mechanisms.

Spleen, the physiological site of RBC removal from the circulation, is abnormal in SCD patients. The functional asplenia is likely to increase the rates of intravascular hemolysis. Sickling of RBCs and intra-organ hemolysis stimulate infiltration by circulating monocytes and their differentiation into macrophages. Endocytosis of RBC lysate products affects macrophage phenotypes. ${ }^{10,11}$ Intravascular $\mathrm{RBC}$ hemolysis also releases lysate products that impair endothelial function leading to chronic vasculopathy. Vascular endothelium and monocytes are activated in SCD patients, and monocyte numbers are increased. ${ }^{12-14}$ Activated macrophages express matriptase-1 (MT-SP1) which is one of the proteases that cleavages and activates circulating macrophage stimulating protein 1 (MSP1). ${ }^{15,16}$

MSP1 was shown to accumulate in glomeruli in the rat model of anti-Thy1 glomerular disease; its neutralization by antibodies reduced serum creatinine and proteinuria, and protected rats from glomerular injury. ${ }^{17} \mathrm{MSP} 1$ is a plasma protein secreted by liver and circulated as a single- chain, biologically inactive pro-MSP1. It is activated by proteolytic cleavage of Arg483-Val484 bond by either serum proteases or proteases expressed on the cell surface. ${ }^{18}$ Pro-MSP1 diffuses into local tissues where it is activated by proteolytic cleavage and plays a role in the tissue injury or repair. ${ }^{18}$ Activated MSP1 binds to and activates a cell surface receptor tyrosine kinase, Recepteur d'Origine Nantais (RON). ${ }^{19}$ We hypothesize that endocytosis of RBC lysis products by kidney-infiltrating macrophages stimulates expression of MT-SP1, which then locally activates circulating MSP1. We further hypothesize that MSP1 binds to RON tyrosine kinase receptor and activates glomerular endothelium in SCD. We test these hypotheses using a humanized mouse model of SCD (Townes) which recapitulates several hematologic manifestations of human SCD, including renal vascular occlusion, as well as vascular, tubular and glomerular changes. ${ }^{20,21}$ Here we showed that glomerular disease in SCD mice was associated with endothelial injury, increase in renal macrophage infiltration, and glomerular MSP1 accumulation. In vitro, treatment of cultured human macrophages with hemin, a breakdown product of hemoglobin, or RBC lysate significantly increased expression of MT-SP1. In cultured human renal glomerular endothelial cells, MSP1 treatment induced phosphorylation of RON downstream signaling ERK and AKT kinases, increased expression of von Willebrand factor (vWF) and cell motility, and induced re-organization of
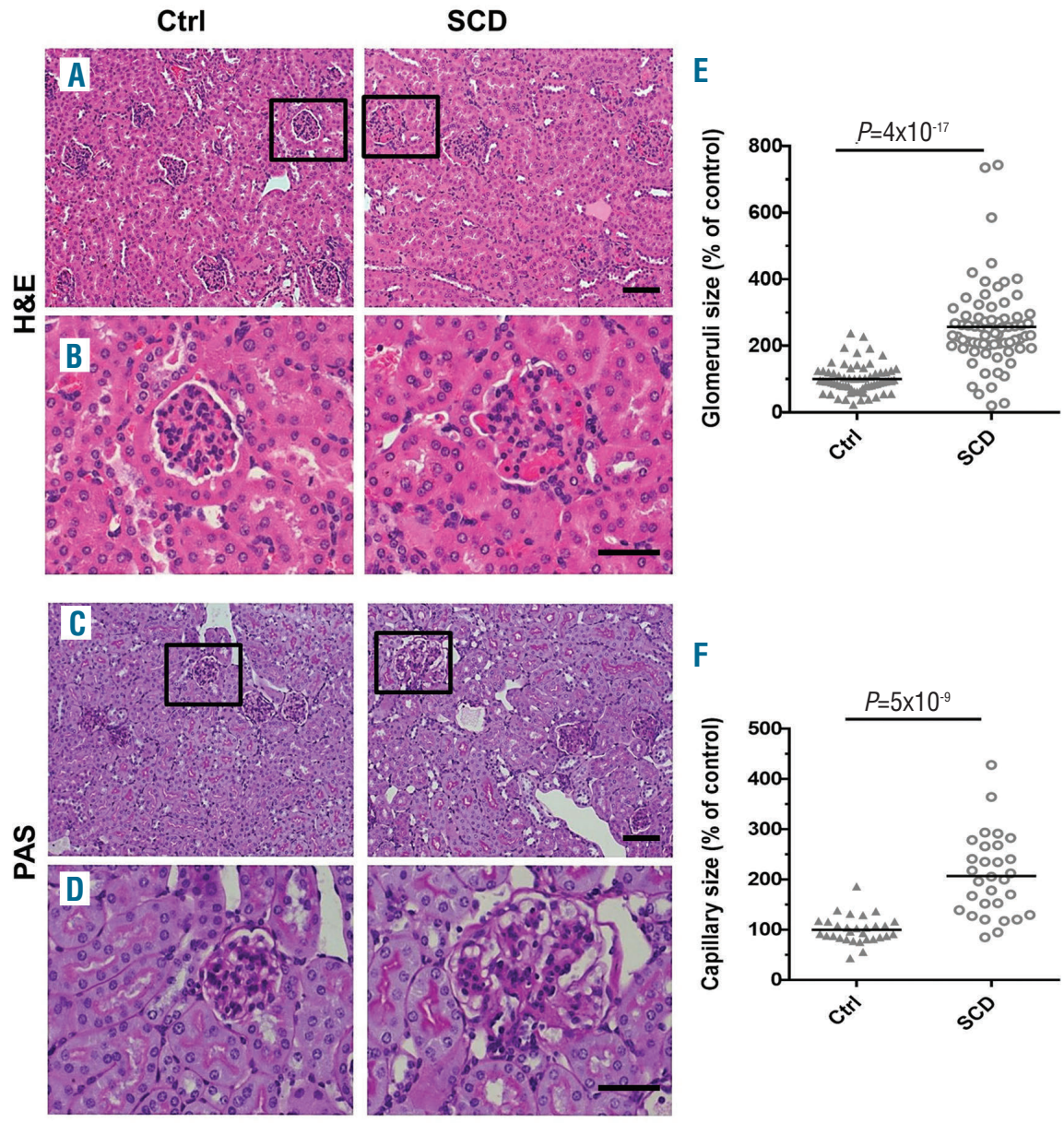

Figure 1. Renal disease in sickle cell disease $(\mathrm{SCD})$ mice is characterized by significant glomeruli hypertrophy and capillary dilation. (A-D) Representative pictures of hematoxylin and eosin staining (H\&E) (A and B), and periodic acid-Schiff staining (PAS) $(C$ and $D)$ of renal sections. Squares show enlarged areas (B and D). Bar sizes on microphotographs are $100 \mu \mathrm{m}(\mathrm{A}$ and $\mathrm{C})$ and $40 \mu \mathrm{m}$. (B and $D)$. ( $E$ and $F)$ Quantification of glomeruli size (E) and capillary size per glomeruli cross section (F) is performed using CellSens Standard software. Five mice per group were used for each staining. For quantification graphs, means are shown. Each dot represents a value obtained from one glomerulus cross-section. Ctrl: control. 
F-actin. RON kinase inhibitor (RONi, BMS-777607) significantly reduced RON signaling. Moreover, injections of $\mathrm{RONi}$ in young SCD mice prevented the development of glomerular disease, substantially reducing glomerular hypertrophy, capillary dilation and congestion, and endothelial injury.
Taken together, these data demonstrated that renal glomerular accumulation of MSP1 and the activation of RON kinase were involved in the induction of renal endothelial injury in SCD mice. Inhibition of RON kinase activation is a novel approach to prevent CKD development in SCD.

\section{Ctrl}
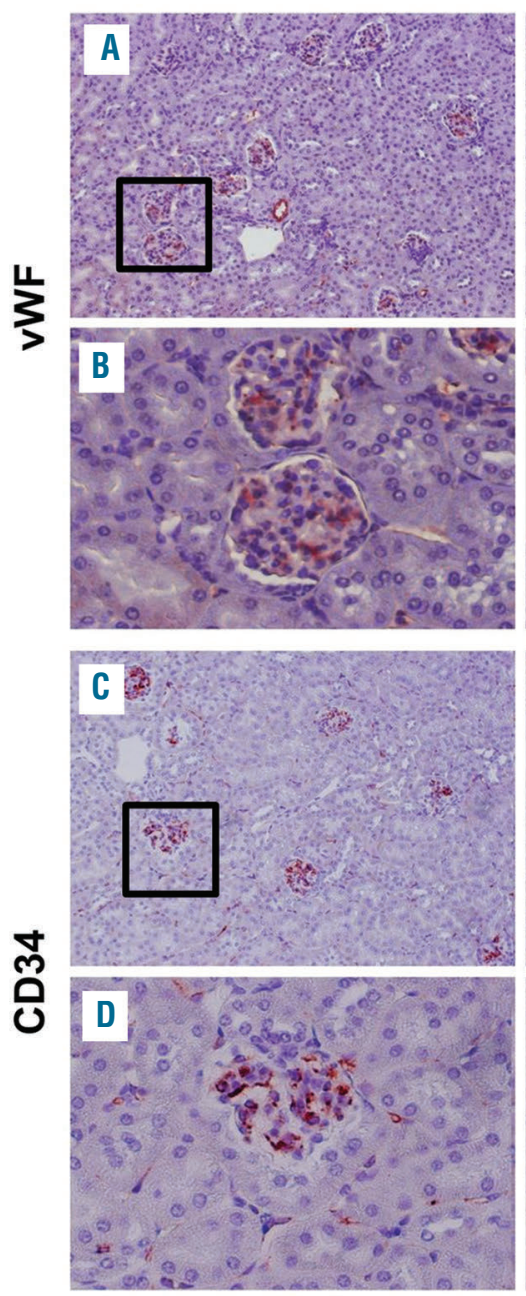

E

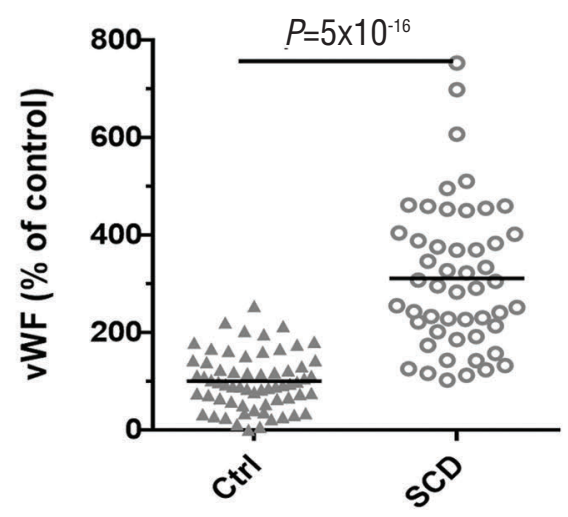

SCD
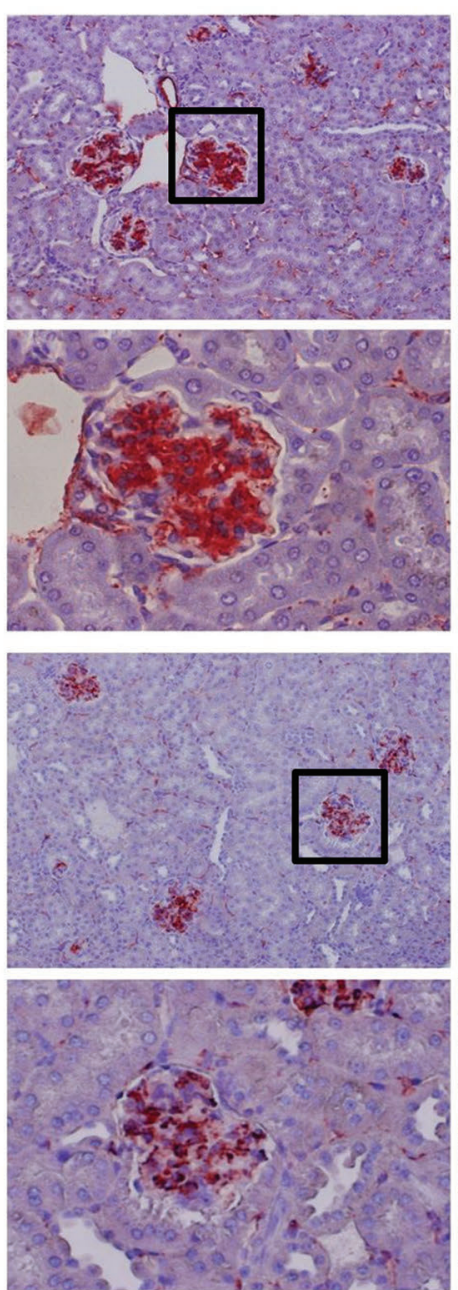

Non-specific Abs
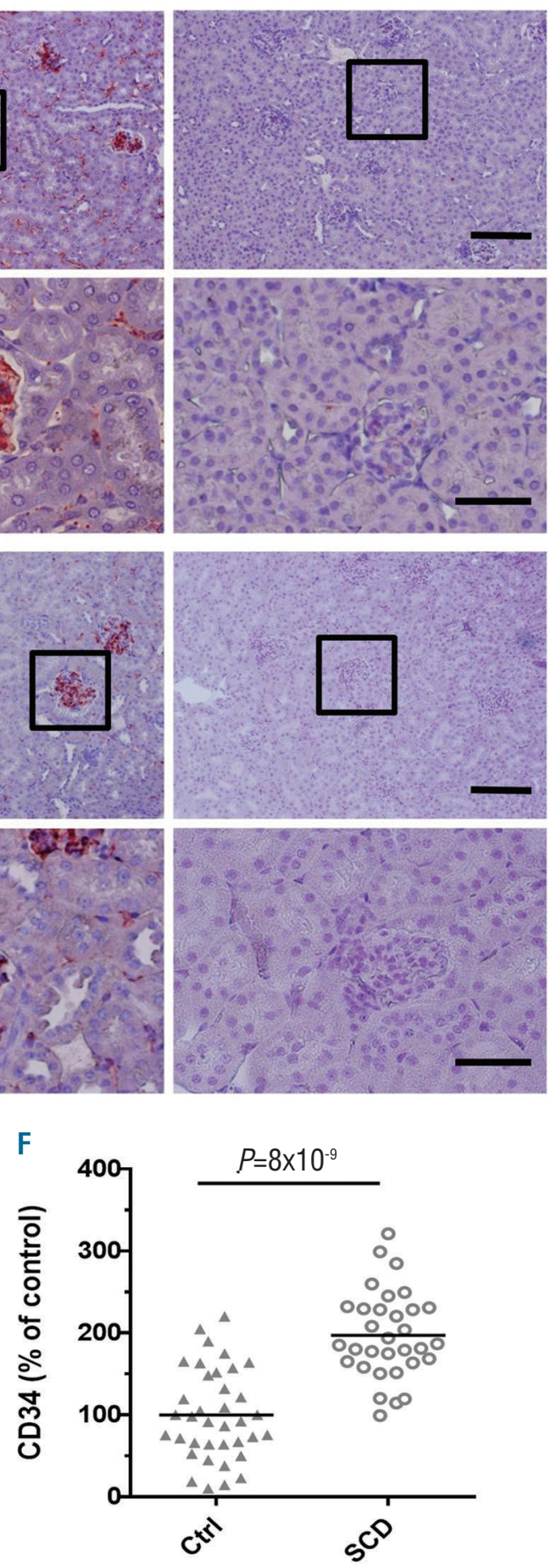

Figure 2. Renal disease in sickle cell disease (SCD) mice is associated with significant endothelial injury. (A-D) Representative pictures of von Willebrand factor (VWF) (A and B) and CD34 (C and D) immunostaining (red) of renal sections. Squares show enlarged areas (B and D). Non-specific primary antibodies (Abs) were used as a negative control. Bar sizes on the microphotographs are $100 \mu \mathrm{m}$ (A and C) and $40 \mu \mathrm{m}$. (B and D). (E and F) Quantification of vWF (E) and CD34 (F) expression in glomeruli cross sections is performed using Image J Fiji version. Five mice per group were used for each staining. For quantification graphs, means are shown. Each dot represents a value obtained from one glomerulus cross-section. Ctrl: control. 


\section{Methods}

Mice and RONi injections

The animal protocol was approved by the Institutional Animal

Care and Use Committee at the Children's National Health
System. Townes mice, here referred to as SCD mice, were obtained from the Jackson Laboratory.

Two-month old mice were injected subcutaneously with 10 $\mathrm{mg} / \mathrm{kg}$ of body weight of RON inhibitor (RONi, BSM-777607,

Santa Cruz Scientific) in 2\% DMSO daily for 14 consecutive days.

\section{Ctrl}
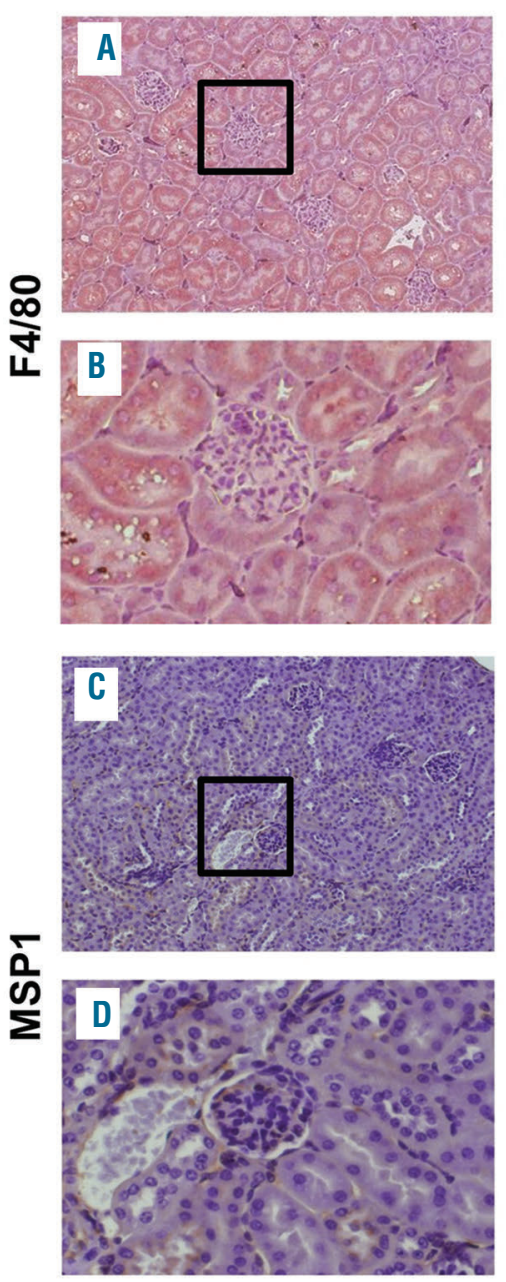

SCD
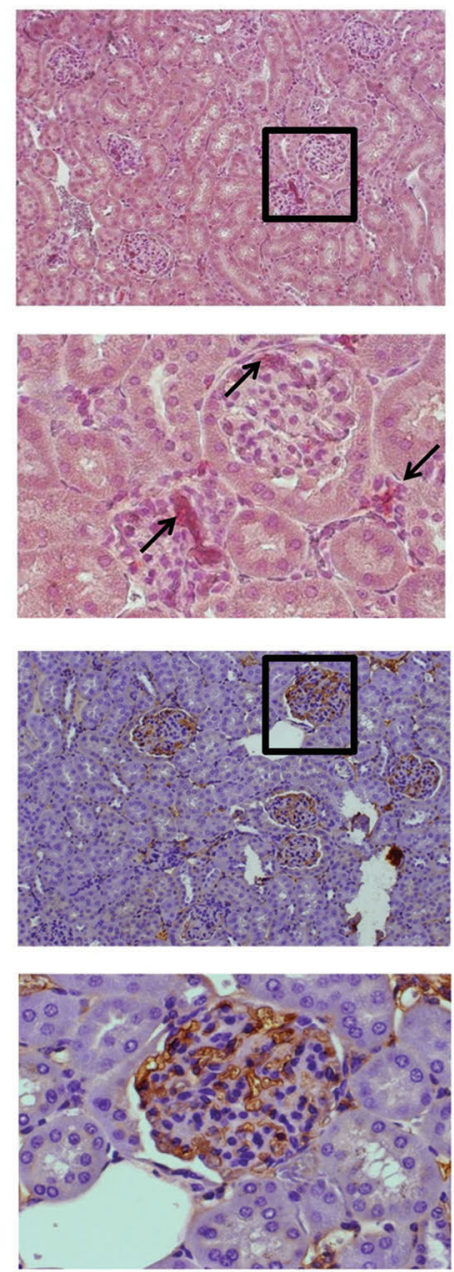

Non-specific Abs
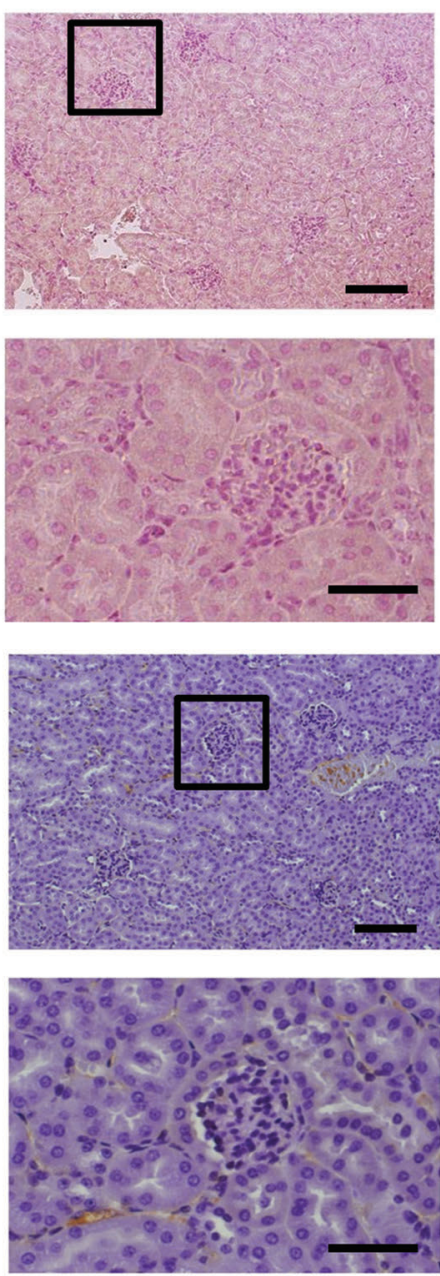

E

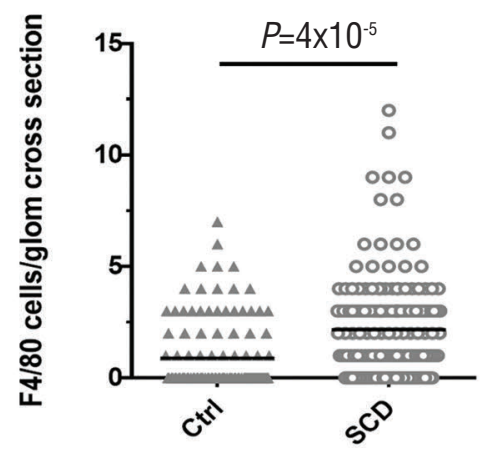

$\mathrm{F}$

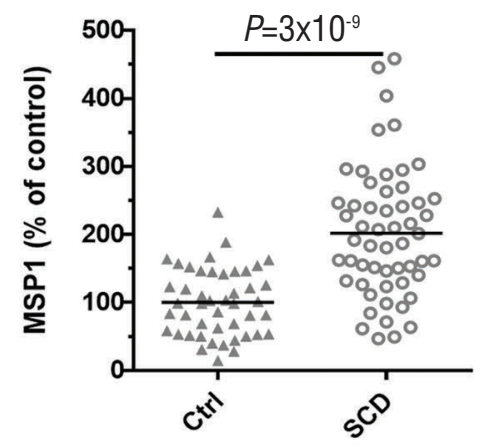

Figure 3. Glomerular macrophages infiltration and MSP1 accumulation is increased in sickle cell disease (SCD) mice. (A-D) Representative pictures of macrophages (F4/80) (A and B, red) and macrophage stimulating protein 1 (MSP1) (C and D, brown) immunostaining of renal sections. Squares show enlarged areas immunostaining (B and D). Non-specific primary antibodies (Abs) were used as a negative control. Bar sizes on the microphotographs are $100 \mu \mathrm{m}$ ( $\mathrm{A}$ and $\mathrm{C}$ ) and $40 \mu \mathrm{m}$. (B and D). ( $E$ and $F)$ Quantification of $F 4 / 80$ positive macrophages per glomeruli cross section (E) and MSP1 accumulation in the glomeruli ( $F$ ) is performed using ImageJ Fiji version software. Five mice per group were used for each staining. For quantification graphs, means are shown. Each dot represents a value obtained from one glomerulus cross-section. Ctrl: control. 
Six SCD and 4 control mice were injected with RONi. Similar groups were injected with $2 \%$ DMSO (vehicle).

\section{Immunohistochemistry}

Paraffin embedded tissue sections were used for immunostaining with rat anti-mouse F4/80 (AbD Serotec), rabbit anti-vWF (Dako), rat anti-mouse ICAM (BioLegend), rat anti-mouse CD34 (Cedarline), and mouse anti-MSP1 (R\&D Systems). AEC and DAB kits were obtained from Vector Laboratory. Images were acquired with an Olympus 1x51 microscope with an Olympus DP 72 camera. Quantification of positive staining was performed using ImageJ Fiji version and CellSens Standard (Olympus) software.

\section{Cell culture}

Human glomerular endothelial cell line (HGEC) was generated as described ${ }^{22}$ and maintained in DMEM media supplemented with 10\% fetal bovine serum (FBS) and antibiotics (all from Thermo-Fisher). THP1 human monocytic cell line was purchased from ATCC and maintained in RPMI-1640 media supplemented with $10 \%$ FBS, antibiotics and $2 \mu \mathrm{M} \beta$-mercaptoethanol (SigmaAldrich). THP-1 cells were differentiated into macrophages by treatment with $10 \mathrm{nM}$ phorbol 12-myristate 13 acetate (PMA, Sigma-Aldrich) for 48 hours (h).

\section{Treatment of THP-1 cells with hemin and RBC lysate}

Hemin was obtained from Frontier Scientific. Blood samples were collected from healthy control subjects. RBCs were isolated by centrifugation, frozen at $-80^{\circ} \mathrm{C}$ for $15 \mathrm{~min}$, and then thawed for lysis. Cellular debris was pelleted by centrifugation, and the hemolysates were stored at $-80^{\circ} \mathrm{C}$. Differentiated THP- 1 cells were treated either with different concentrations of hemin or hemolysates for $18 \mathrm{~h}$.

\section{Immunofluorescent staining and western blots}

Rabbit MT-SP1 (Calbiochem) antibody was used for immunostaining and western blot (WB) of THP1 cells. HGEC were treated with $1 \mu \mathrm{M}$ of human recombinant MSP1 (R\&D Systems) with or without RON inhibitor (200 nM) for varying times. WB analysis was performed with rabbit anti-p44/p42 MAPK (Erk1/2), rabbit anti-phospho-p44/p42 Erk1/2, rabbit anti-pan-Akt, and rabbit anti-phospho-Akt antibodies (all from Cell Signaling Technology). Mouse anti- $\beta$-actin antibodies and phalloidin-FITC conjugate were obtained from Sigma-Aldrich.

\section{Wounding migration assay}

The HGEC monolayers were wounded by strokes across the diameter of the well with 2.5 -mm-wide pipet and medium with MSP1 $(1 \mu \mathrm{M})$ was added. The width of the wound was visualized with pictures taken at pre-treatment and $5 \mathrm{~h}$ post treatment. A total of 20 random measurements were analyzed for each wound at each time point.

\section{Isolation of mouse renal glomeruli and glomeruli permeability assay}

Mouse renal glomeruli were isolated from control mice using a sieving technique. ${ }^{23}$ Glomerular permeability was measured by a determination of albumin permeability, as described previously ${ }^{24}$ with slight modification (Online Supplementary Methods).

\section{Statistical analysis}

Results were expressed as mean \pm Standard Deviation. Differences between two groups were compared by unpaired parametric $t$-test, between multiple groups by one-way ANOVA (GraphPad software). Differences between groups were considered significant at $P<0.05$.

\section{Results}

SCD mouse kidneys have increased macrophage infiltration and MSP1 accumulation in the glomeruli

Kidneys were collected from 4-month old SCD and control mice ( $n=5$ per group) and renal injury was evaluated. SCD mice develop RBC sickling, anemia, leukocytosis, behavioral changes, and multi-organ pathology characteristic of SCD patients. ${ }^{21,25,26}$ Glomerular abnormalities in 4month old SCD mice were characterized by: glomerular hypertrophy [Figure 1A, B, and E, hematoxylin and eosin (H\&E) staining]; expansion of mesangium [Figure 1C and $\mathrm{D}$, periodic acid Schiff (PAS) staining, and Online Supplementary Figure S1, PCNA staining]; capillary dilation, and thickening of capillary loops and glomerular basement membrane (Figure 1C, D and F, PAS staining). Glomerular capillaries, peritubular cortical capillaries, and capillaries in the medulla and papilla were markedly congested, and sickling of RBCs was observed especially in the medulla and papilla (Online Supplementary Figure S2, H\&E staining). Capillary congestion and dilation together with hemolysis might induce endothelial cell injury and secretion of von Willebrand Factor (vWF) into the surrounding blood and sub-endothelium. ${ }^{27,28}$ Indeed, glomerular capillary expression of VWF was significantly increased in SCD mice (Figure 2A, B and E, immunostaining, red). Murine glomerular capillary showed positive immunostaining for endothelial marker $\mathrm{CD} 34^{29}$ that was significantly increased in SCD mice (Figure 2C, D and F, immunostaining, red). Because CD34 is also expressed on hematopoietic progenitors cells which are increased in the circulation in SCD mice $^{30}$ these cells may also be a source of increased CD34 staining in the congested capillary. We also observed a significant renal glomerular and interstitial infiltration of activated macrophages in SCD mice (Figure $3 \mathrm{~A}, \mathrm{~B}$ and $\mathrm{E}$, F4/80 immunostaining, arrows, and Online Supplementary Figure S3). Glomerular infiltrated macrophages were negative for the inducible nitric oxide synthase (iNOS), a marker of M1 pro-inflammatory macrophage (Online Supplementary Figure S4). MSP1 was accumulated in SCD renal glomerular capillary (Figure $3 \mathrm{C}, \mathrm{D}$ and F, immunohistostaining, brown). High levels of MSP1 accumulation were found in $46 \pm 8 \%$ of glomeruli in SCD mice. In contrast, less than $20 \%$ of glomeruli demonstrated low levels of MSP1 accumulation in control mice. Together, these findings show that renal disease in SCD mice is associated with significant endothelial injury, macrophage infiltration, and accumulation of MSP1 in the glomerular capillaries.

\section{Hypoxia, hemin, and red blood cell lysate stimulate expression of matriptase 1 in human macrophages}

MSP1 is produced by the liver and secreted into circulation where it is activated by proteolytic cleavage. ${ }^{18}$ Macrophage membrane-bound matriptase 1 (MT-SP1) is one of the proteases which activate MSP1 protein. ${ }^{16,31} \mathrm{We}$ tested whether renal hypoxia and RBC hemolysis increased expression of MT-SP1. Meta-analysis of the NCBI Geo database demonstrated a 2-fold increase in MTSP1 expression in human monocyte-derived differentiated macrophages compared to non-differentiated monocytes (Figure 4A). Meta analysis also showed that MT-SP1 expression was further increased in macrophages that were cultured under hypoxia (Figure 4B). Non-differentiated human pro-monocytic cell line (THP-1 cells) expressed 
a low level of MT-SP1, which was increased after THP-1 differentiation into macrophages by PMA treatment (Figure 4C and D, compare lanes 1 and 2). Treatment of THP-1-derived macrophages with hemin or RBC lysate further increased MT-SP1 expression (Figure 4C-F). Immunofluorescent staining of THP-1-derived macrophages demonstrated membrane and cytoplasmic distribution of MT-SP1 (Figure 4G, green) which was significantly increased upon treatment with hemin $(10 \mu \mathrm{M})$ or RBC lysate (Figure 4G). Collectively, hemolysis products (tested in this study) and hypoxia (meta-analysis data) demonstrated increased expression of MT-SP1 in human macrophages. Higher levels of MT-SP1 expression might induce local activation and accumulation of circulating MSP1.

\section{MSP1 induces endothelial cell motility and activated downstream RON signaling of ERK and AKT}

To assess the impact of MSP1 on the endothelium, we examined its effect on cultured human glomerular endothelial cell line (HGEC) recently generated in our laboratory. ${ }^{22}$ Treatment with $1 \mu \mathrm{M}$ MSP1 did not induce proliferation of HGEC (Figure 5A). In contrast, MSP1 treatment significantly increased motility of HGEC in a 2D wound assay (Figure 5B and C). F-actin plays a central role in the endothelial cell motility and permeability. ${ }^{32}$ Inflammatory mediators can alter F-actin formation and distribution. ${ }^{32}$ In confluent HGEC, F-actin formed mostly a cortical rim with few stress fibers (Figure 5D, green). MSP1 stimulated re-organization of F-actin and formation of stress fibers. (Figure 5D, green). Treatment cells with specific RON kinase inhibitor (200 nM; RONi) inhibited MSP1-induced formation of stress fibers and vWF expression (Figure 5D, F-actin and vWF staining). MSP1 treatment also increased expression of vWF in HGEC (Figure $5 \mathrm{D}$, red), and this increased expression was inhibited by RONi (Figure 5D). Next, we examined activation of RON kinase signaling in HGEC. Binding of MSP1 to RON leads to phosphorylation of the downstream kinases, ERK and AKT. ${ }^{33}$ Levels of ERK and AKT phosphorylation in HGEC
A

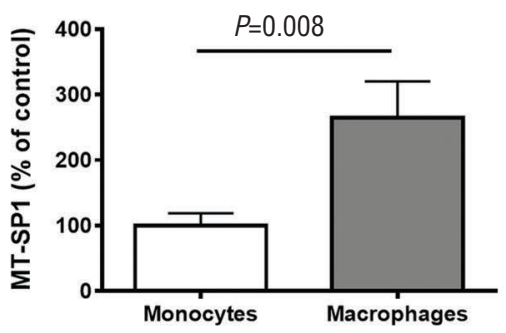

C

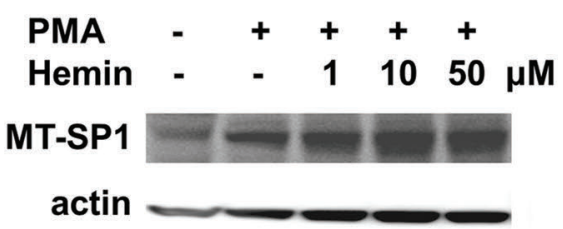

E

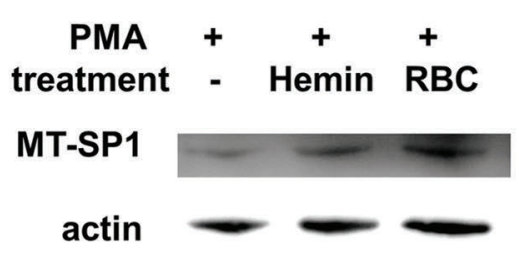

B

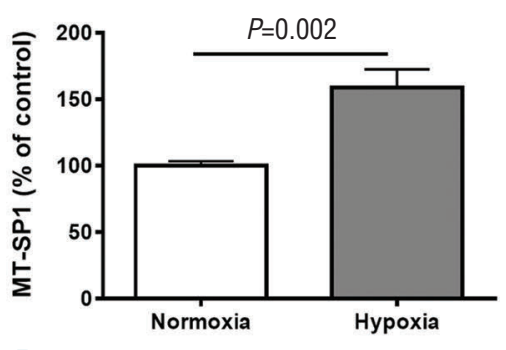

D

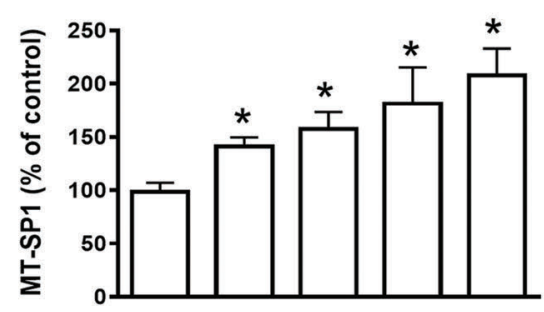

$\mathrm{F}$

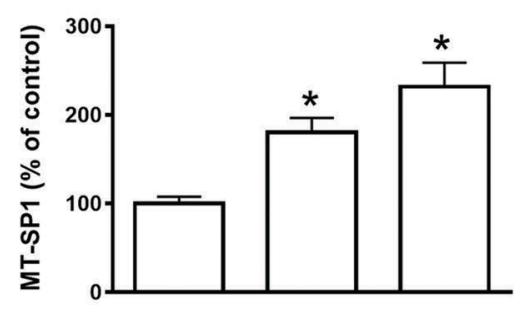

G

THP-1

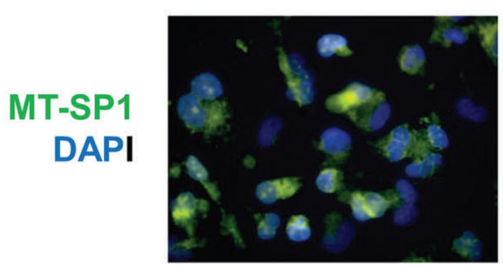

THP-1+hemin

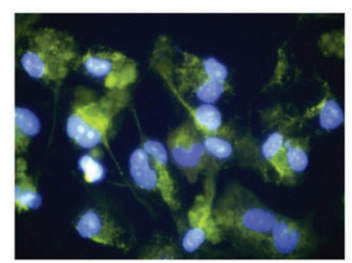

THP-1 +RBC

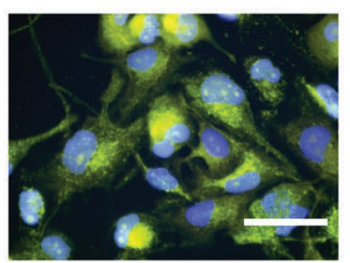

Figure 4. Hemin, red blood cell (RBC) count and hypoxia treatment increase expression of matriptase MT-SP1 in human THP1-derived macrophages. (A and $B$ ) Meta-analysis of membrane type serine protease 1 (MTSP1) expression in human primary monocyte-derived macrophages using Geo database NCBI (A) Data Set GDS3203 and (B) Data Set GDS2036. For quantification graphs, mean and Standard Deviation (SD) are shown. (C and E) Western blot of MTSP1 in human THP-1-derived macrophages treated with different concentrations of hemin (C) or RBC lysate (D). $\beta$-actin was used for normalization. (D and F) Quantification of MT-SP1 on Western blot. For quantification graphs, mean and SD are shown. ${ }^{*} P<0.05$. Results are representative of three independent experiments. (G) Immunostaining of MTSP1 in THP-1-derived macrophages treated with hemin $(10 \mathrm{nM})$ or RBC lysate (green). DAPI was used for nuclear staining. Bar size 40 $\mu \mathrm{m}$. PMA: phorbol 12-myristate 13-acetate. 

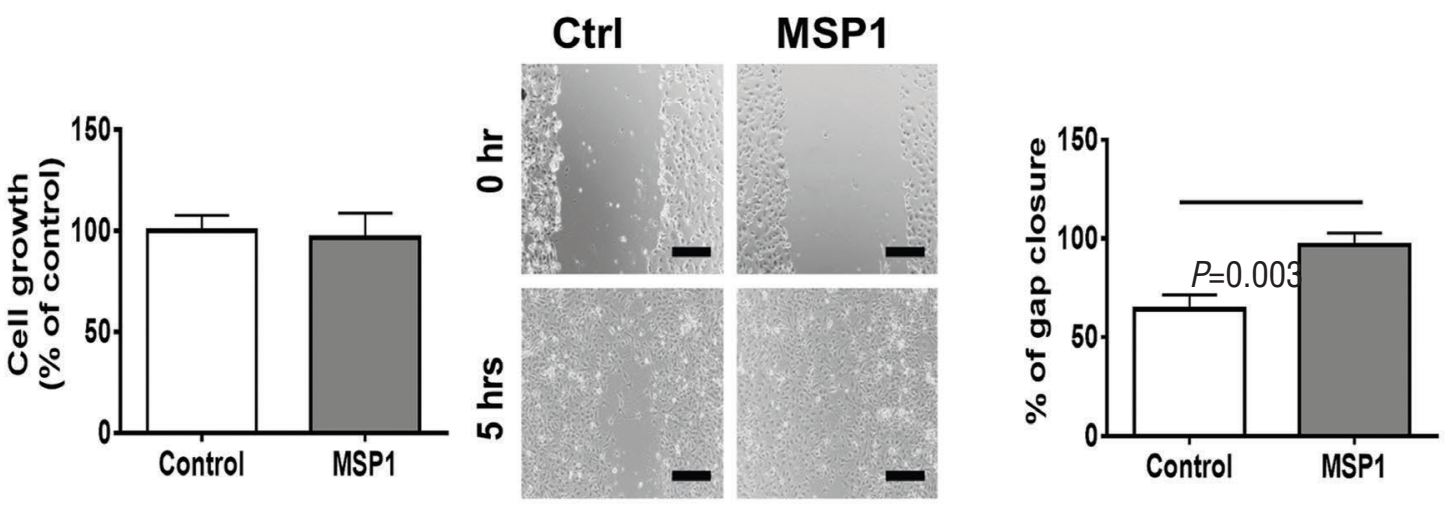

D
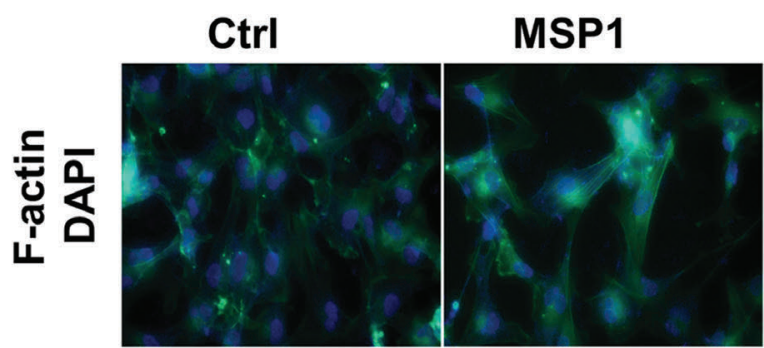

MSP1+RONi

Non-specific

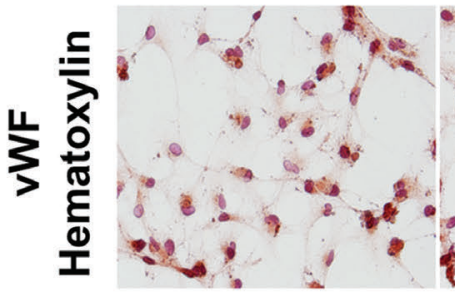

E

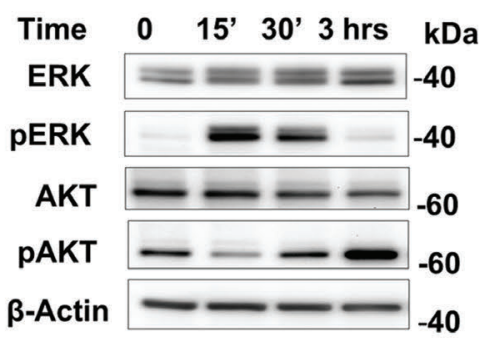

G

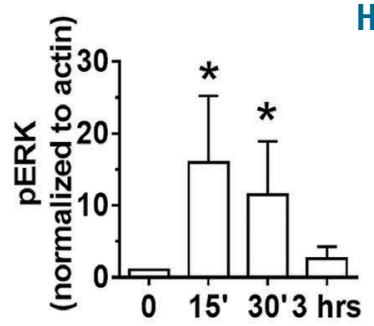

H

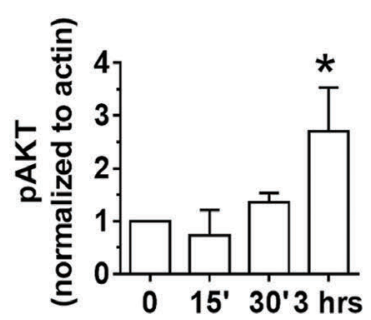

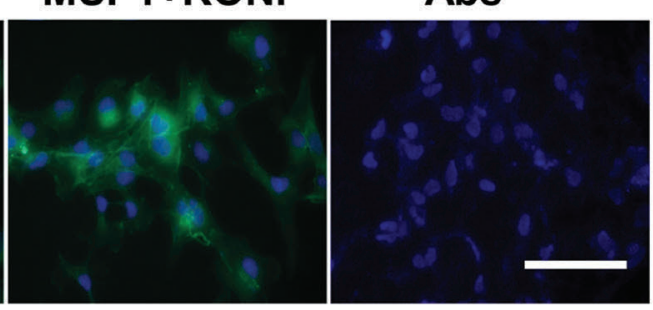

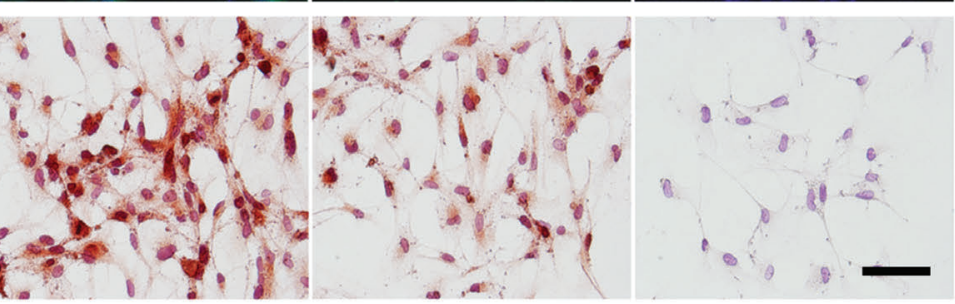

$\mathbf{F}$

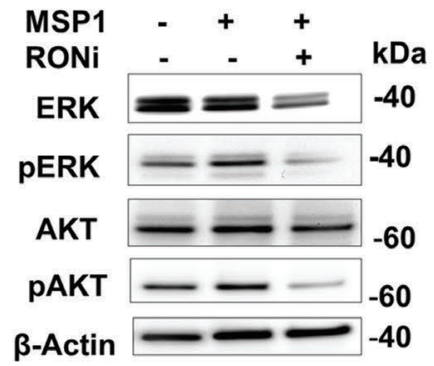

I

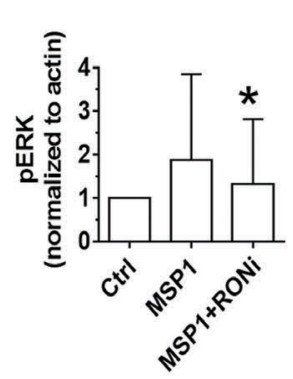

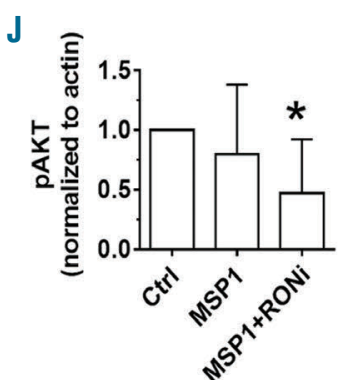

Figure 5. MSP1 treatment of cultured human glomerular endothelial cell line (HGEC) induces cell motility and vWF expression, F-actin re-organization, and RON kinase signaling in HGEC. (A) Cell growth measured by MTT assay. Five wells are used for either control or treatment with $1 \mu \mathrm{M}$ of recombinant MSP1 in each experiment. Results are representative of three independent experiments. (B) Representative picture of wound migration assay of control cells and cells treated with 1 $\mu \mathrm{M}$ of MSP1. Bar size $300 \mu \mathrm{m}$. (C) Quantification of wound migration assay. Three wells are used per treatment in each experiment. Results are representative of three independent experiments. (D) Immunostaining of F-actin (green) and vWF (red) in control and treated MSP1 (1 $\mu$ M) treated cells with or without RONi (200 nM). DAPI (for F-actin) and Hematoxylin (for vWF) were used for nuclear staining. Non-specific primary antibodies were used for negative control. Bar size 40 um for F-actin and $100 \mu \mathrm{m}$ for vWF. (E and F) Western blots of phosphorylated and non-phosphorylated forms of ERK and AKT kinases in HGEC. (E) Cells were treated with MSP1 $(1 \mu \mathrm{M})$ and collected at different time points after treatment. (F) Cells were treated with MSP1 (1 $\mu \mathrm{M})$ with or without RON inhibitor (RONi, $200 \mathrm{nM})$ for 30 min. (G-J) Quantification of pERK and pAKT on Western blot. For quantification graphs, mean and SD are shown. ${ }^{\star} P<0.05$. Results are representative of three independent experiments. $\beta$-actin used for loading normalization. 


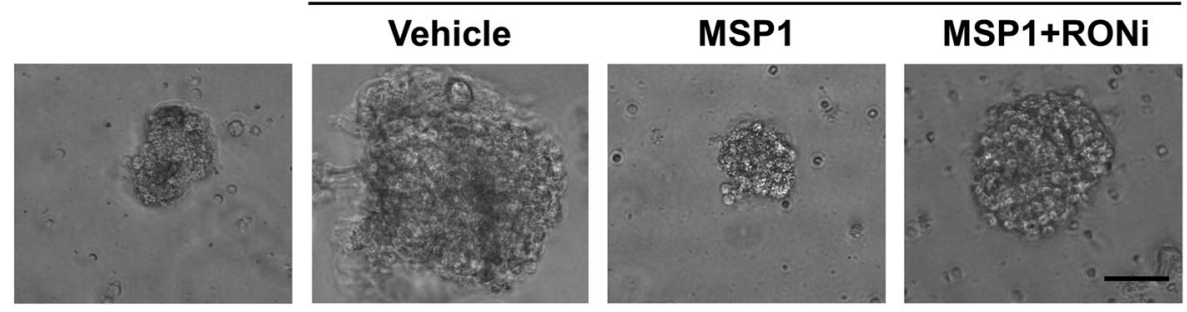

B

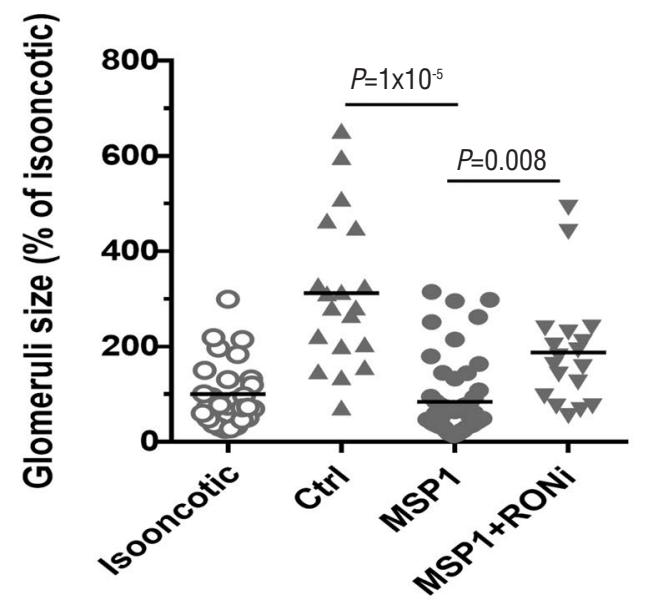

Figure 6. MSP1 increases glomerular permeability in whole glomeruli assay. (A) Representative pictures of glomeruli isolated from control mice placed in isooncotic and hypooncotic solutions. Glomeruli were pretreated with vehicle (PBS), or with MSP1 (1 $\mu M$ ) with or without RON inhibitor (RONi 200 $\mathrm{nM})$. Bar size $40 \mu \mathrm{m}$. (B) Quantification of glomerular volume change in hypooncotic solution. CellSens Standard software was used for measurement of the glomeruli area and glomeruli volume was calculated. Percent of volume changes in isooncotic solution is shown. For quantification, graphs means are shown. Each dot represents a value obtained from one glomerulus.

were significantly increased after MSP1 treatment (Figure 5E-G). Phosphorylation of ERK and AKT was significantly reduced after treatment with RONi (Figure $5 \mathrm{H}-\mathrm{J}$ ). Taken together, MSP1 activated $\mathrm{RON}$ receptor signaling in cultured HGEC leading to the re-organization of F-actin and increasing cell motility and vWF expression.

\section{MSP1 increases permeability in SCD mouse glomeruli}

Glomerular hyperfiltration is an early stage manifestation in the development of SCD glomerulopathy. ${ }^{34,35}$ To test whether MSP1 increases glomeruli permeability, we utilized a mouse whole glomeruli permeability assay. ${ }^{24}$ Renal glomerular permeability measurement was based on the determination of albumin permeability. In the absence of capillary filtration, the diffusional loss of albumin from glomeruli capillary is negligible. ${ }^{24}$ Placement of intact glomeruli into the hypooncotic solution increases glomeruli volume due to water accumulation inside glomeruli according to oncotic gradient. ${ }^{24}$ Treatment of glomeruli with permeating agents that increase glomerular filtration significantly increases albumin loss and reduces oncotic gradient, leading to a reduced glomerular volume in the hypooncotic solution. ${ }^{24}$ Renal glomeruli were isolated from control mice and treated with recombinant MSP1 $(1 \mu \mathrm{M})$ in the presence or absence of $\mathrm{RONi}(200 \mathrm{nM})$ for 30 min (see Methods for details). PBS was used as a vehicle control. Placement of vehicle-treated glomeruli in hypooncotic solution significantly increased glomerular volume by more than 3.5-fold (Figure 6A and B). MSP1 treatment reduces glomerular volume, whereas $\mathrm{RONi}$ treatment restored the ability of glomeruli to enlarge in the hypooncotic solution (Figure 6A and B). Taken together, pre-treatment of mouse glomeruli with MSP1 significantly increased glomerular permeability for albumin, and RONi reduced MSP1-associated glomerular permeability.

\section{Treatment of SCD mice with RONi significantly} ameliorates glomerular endothelial injury

To test whether $\mathrm{RONi}$ prevents development of glomerular endothelial injury in young SCD mice, 2month old SCD mice were injected with either RONi (10 $\mathrm{mg} / \mathrm{kg}$ of body weight in $2 \%$ DMSO) or vehicle $(2 \%$ DMSO, $n=6$ per group) subcutaneously for 14 days. Control non-SCD mice were also injected with either $\mathrm{RONi}$ or vehicle ( $\mathrm{n}=4$ per group). We used younger (2month old) mice to test whether RONi prevents development of glomerular disease, because older (4-month old) mice had already developed profound glomerular disease (Figures 1 and 2). Only 20\% of 2-month old mice developed microalbuminuria (1 of 5 mice), and $40 \%$ of 12 -week old non-treated SCD mice developed microalbuminuria (2 of 5 mice) (data not shown). In contrast, we found that all non-treated mice had glomerular endothelia cell injury at 12 weeks of age. Because endothelial injury was detected before the onset of albuminuria, we focused on the role of $\mathrm{RON}$ signaling in the development of endothelial injury. Administration of RONi in SCD mice did not affect body weight (Figure 7A), but significantly reduced kidney size (Figure $7 \mathrm{~B}$ and $\mathrm{C}$ ). Moreover, administration of $\mathrm{RONi}$ in SCD mice significantly reduced glomerular hypertrophy and capillary congestion (Figure 8A and $\mathrm{E}$ and Online Supplementary Figure S5, H\&E staining). Capillary dilation and thickening of capillary loops and glomerular basement membrane were significantly reduced in SCD mice treated with RONi compared to mice with vehicle injection (Figure 8B and F and Online Supplementary Figure S5, PAS 
staining). RONi treatment did not affect mesangial expansion in SCD mice (Figure $8 \mathrm{~A}$ and $\mathrm{B}, \mathrm{H} \& \mathrm{E}$ and Online Supplementary Figure S6, PAS staining). However, RONi administration in SCD mice significantly reduced capillary expression of vWF (Figure 8C and G and Online Supplementary Figure S5, immunostaining, red), and Intercellular Adhesion Molecule 1 (ICAM1) (Figure 8D and $\mathrm{E}$ and Online Supplementary Figure S5, immunostaining, red), which are the markers of endothelial injury. ${ }^{36,37}$ Thus, inhibiton of RON receptor in SCD mice significantly ameliorated development of endothelial and glomerular injury.

\section{Discussion}

Renal disease in SCD patients includes a variety of glomerular and tubular complications, but the mechanism of their development is not fully understood. The most important finding in our study is that MSP1 and its receptor RON kinase may play a role in the activation of renal endothelium and development of glomerular pathology in SCD mice. Moreover, treatment of mice with RONi, an inhibitor of RON kinase, significantly ameliorated glomerular hypertrophy, capillary dilation and congestion, and endothelial injury. These findings reveal a previously unknown mechanism which contributes to glomerular endothelial injury in SCD.

Sickle cell disease mice spontaneously develop FSGS that may be directly associated with RBC sickling and chronic hemolysis. The focal nature of glomerulosclerosis in SCD mice and SCD patients apparently excludes the effect of global factors, such as hypoxia, cell-free heme, iron, and other circulating factors that would lead to a global and not focal glomerulosclerosis with involvement of only $50 \%$ of glomeruli in SCD mice. Thus, locally-produced factor(s) are more likely to contribute to the development of FSGS.

In agreement with a previous report, ${ }^{21}$ we demonstrate here that macrophage infiltration in renal glomeruli was increased in SCD mice. Sickling and adhesion of RBCs, and accumulation of RBC lysate products within the kidney might stimulate renal infiltration of monocyte-derived macrophages. Monocyte-derived renal macrophages are present in all forms of kidney disease with inflammation, and renal capillary macrophage infiltration is a characteristic pathology of FSGS ${ }^{38}$ In many human biopsy studies, number of glomerular or interstitial macrophages correlate with poor outcomes, suggesting their possible role in the disease progression. ${ }^{39,40}$ However, the role of infiltrating macrophages in the progression of renal disease is not well understood. Phagocytosis of senescent sickled RBCs, RBC exosomes and endocytosis of cell-free hemoglobin increases inflammatory response in the cultured human monocytes/macrophages. ${ }^{12}$ Activation of proteases is a universal inflammatory response in macrophages. ${ }^{41} \mathrm{We}$ demonstrate here that products of $\mathrm{RBC}$ hemolysis significantly increased expression of macrophage membranebound protease, MT-SP1 in cultured human macrophages. Meta-analysis data also showed that hypoxia and monocyte differentiation increased MT-SP1 expression in primary human macrophages. MT-SP1 is a type II membrane serine protease that plays important roles in cell migration and tumor cell metastasis. ${ }^{42}$

MT-SP1 is one of the proteases that activate circulating
A

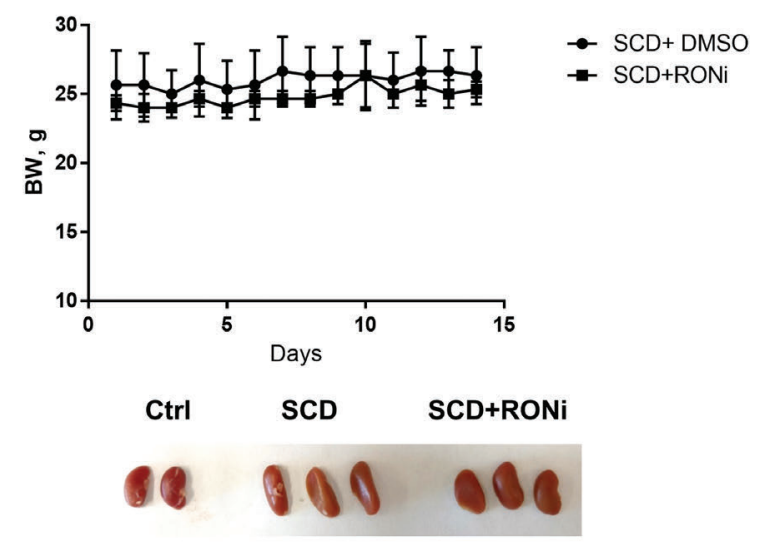

C

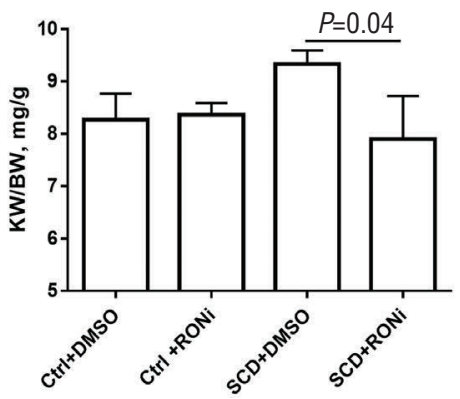

Figure 7. Treatment of sickle cell disease (SCD) mice with RON inhibitor reduces kidney hypertrophy. (A) Treatment of SCD mice with RON inhibitor (RONi) does not affect body weight (BW). (B) Representative picture of kidneys of controls and SCD mice treated either with (RONi) or vehicle (2\% DMSO). (C) Quantification of kidney weight. Kidney weights (KW) to BW ratios are shown.

MSP1..$^{15}$ MSP1 expression has been found in the renal tubular cells. ${ }^{43,44}$ In agreement with previous studies, we did not observe MSP1 expression or accumulation in glomeruli of control mice. In contrast, we found that MSP1 was accumulated in approximately $46 \pm 8 \%$ of renal glomerular capillaries in SCD mice. This accumulation rate was similar to the percentage of injured glomeruli in SCD mice. Glomerular accumulation of MSP1 was previously shown in the rat model of anti-Thy1 glomerular disease, and the neutralization of MSP1 by the injected antibodies reduced serum creatinine and proteinuria, and protected animals from glomerular injury. ${ }^{17}$ However, the mechanism of MSP1-associated glomerular injury was not clarified. RON is expressed in human renal tubular cells and glomerular mesangial cells. ${ }^{43,44}$ MSP1 treatment induces growth, motility and collagen invasion of mesangial cells. ${ }^{43}$ Expression of functional RON in endothelial cells is unknown. MSP1 that is accumulated in glomerular capillary of SCD mice may potentially affect endothelial cells, or leak from capillary to affect mesangial cells or podocytes. The increased glomeruli size associated with dilated glomerular capillary and mesangial proliferation was reported both in SCD patients and mouse model of SCD. ${ }^{20,21,45}$ In our study, inhibition of RON in SCD mice significantly reduced glomerular hypertrophy, as well as capillary dilation and congestion without reduction of mesangial expansion. It is possible that the short time of treatment was not enough to produce statistically signifi- 
cant differences in mesangial cell proliferation, or that factors other than MSP1 could stimulate mesangial growth in SCD mice. Thus, we hypothesized that MSP1 played a role in the activation of endothelial cells. The effect of MSP1 on renal glomerular endothelial cells is still not known.

To test the effect of MSP1 on endothelium, we used cultured HGEC. MSP1 had previously been shown to stimulate motility of murine resident peritoneal macrophages and kidney epithelial cells. ${ }^{18,46}$ We demonstrated that MSP1 treatment increased motility of HGECs and induced formation of F-actin stress fibers that is essential for motility and permeability of endothelial cells. ${ }^{32}$ Further studies are needed to determine whether MSP1/RON signaling induces permeability of cultured endothelial cells. Interestingly, MSP1 increased vWF expression levels in HGEC. High levels of vWF were also found in SCD murine glomeruli. RONi treatment reduced endothelial
A

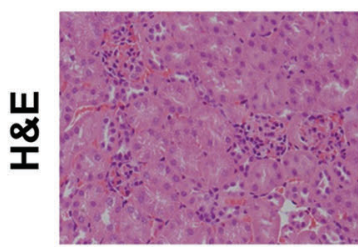

B

C
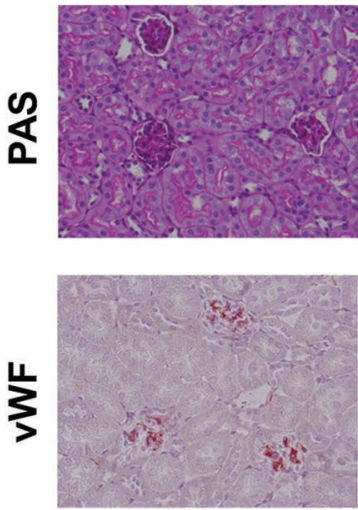

D

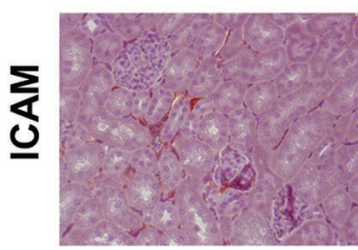

Ctrl+RONi
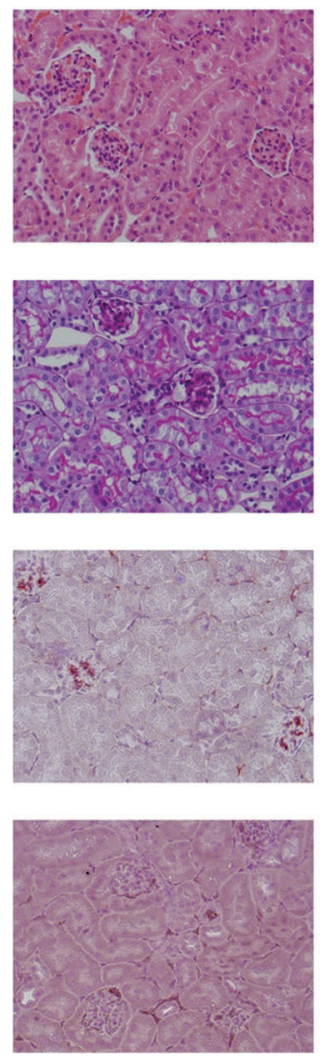

SCD+DMSO
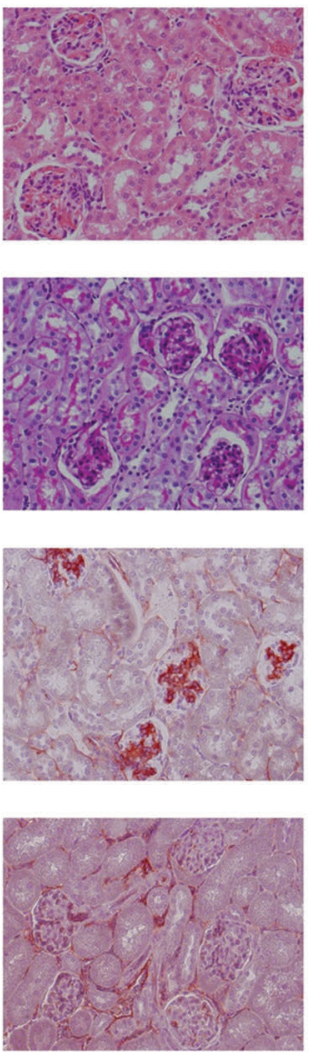

\section{SCD+RONi}
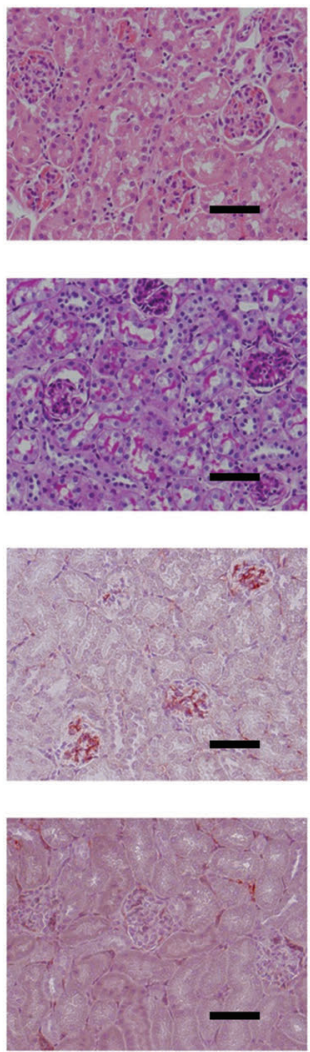

E

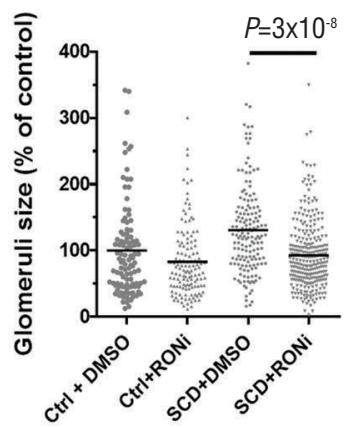

$\mathbf{F}$

G

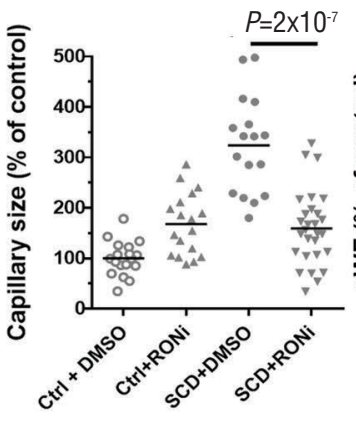

H

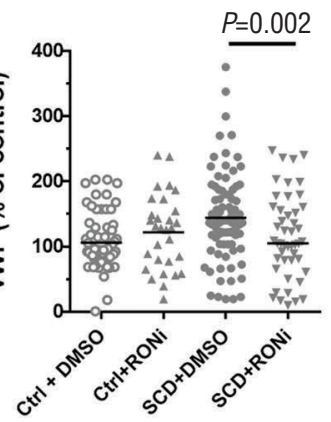

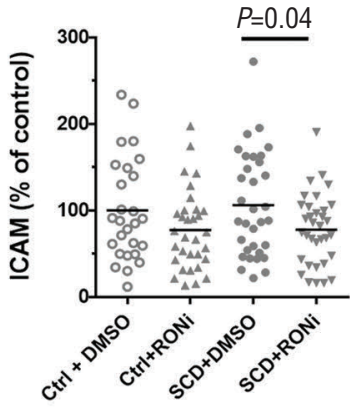

Figure 8. Treatment of sickle cell disease (SCD) mice with RON inhibitor (RONi) reduces renal endothelial injury. Representative pictures of renal sections of control and SCD mice treated with either RONi or vehicle (DMSO) are shown. (A) Hematoxylin\&Eosin (H\&E) staining. (B) Periodic Acid-Schiff (PAS) staining. (C) von Willebrand factor (vWF) immunostaining (red). (D) Intercellular Adhesion Molecule (ICAM) immunostaining (red). Bar sizes 50um. (E and F) Quantification of glomeruli size (E) and capillary size per glomeruli cross section (F) is performed using CellSens Standard software. (G and H) Quantification of vWF (G) and ICAM (H) expression in glomeruli cross sections is performed using ImageJ Fiji version software. Six mice per group were used for each staining. Each dot represents a value obtained from one glomerulus cross-section. For quantification graphs, means are shown. 
vWF levels in vivo and in vitro. vWF mediates adhesion of sickle RBCs to endothelial cells, inducing oxidant stress, and increasing expression of ICAM-1, VCAM and Eselectin. ${ }^{47}$ Indeed, RONi treatment in SCD mice was associated with reduced vWF levels in glomerular capillaries, and decreased RBC adhesion and ICAM-1 levels. Therefore, the mechanism of $\mathrm{RON}$ inhibition may be associated with prevention of glomerular capillary congestion, leading to improvement of renal hemodynamics. A correlation between an alteration of renal hemodynamics and a renal histological injury has been demonstrated in a model of renal ischemia in SCD. ${ }^{48}$ In addition, our results demonstrate that MSP1 treatment of glomeruli isolated from control mice significantly increased albumin permeability that was effectively prevented by RON inhibition. Hyperfiltration is associated with glomerular hypertrophy and glomerulosclerosis. ${ }^{49} \mathrm{We}$ demonstrate a significant reduction in glomerular size in SCD mice after treatment with RON inhibitors, suggesting a possible change in hyperfiltration. Reduction of glomerular size after 14-day treatment with RONi is unlikely to be due to structural remodeling or reduced proliferation of endothelial cells. To the best of our knowledge, this is the first study demonstrating function of MSP1/RON in the glomerular endothelial cells. Future studies will clarify the mechanism of MSP1-associated endothelial cell activation and its role in the development of glomerular injury.

The present study established for the first time that inhibition of RON kinase significantly ameliorates SCD renal pathology in mice. Short-term inhibition of RON kinase reduced endothelial injury in young SCD mice during the early stage of renal disease before the onset of albuminuria. We do not know how long this effect persists after RONi withdrawal. Whether short-term inhibition of RON kinase will ameliorate already developed renal disease in older mice is currently under investigation. Future studies will elucidate a role of Ron kinase in renal disease in SCD patients. These findings also highlight a new potential therapeutic target for CKD in SCD. A recent pre-clinical study ${ }^{50}$ and Phase 1 clinical trial (clinicaltrials.gov identifier: 01721148) of BMS-777607 RON inhibitor for treatment of human cancers demonstrated its safety and good tolerability, providing a proof of principal for the potential use of this pharmacological approach.

\section{Funding}

This work was supported in part by CHaRM pilot grant awarded to MJ through NIH grant 1P50HL118006 (to SN) and NIH grants 1R01HL125005 (to SN), 5G12MD007597 (to $S N)$, and R41MD008829-01 (to ZMQ). The content is solely the responsibility of the authors and does not necessarily represent the official views of the National Institutes of Health.

\section{References}

1. Hamideh D, Alvarez O. Sickle cell disease related mortality in the United States (1999-2009). Pediatr Blood Cancer. 2013;60(9):1482-1486.

2. Elmariah H, Garrett ME, De Castro LM, et al. Factors associated with survival in a contemporary adult sickle cell disease cohort. Am J Hematol. 2014;89(5):530-535.

3. Becton LJ, Kalpatthi RV, Rackoff E, et al. Prevalence and clinical correlates of microalbuminuria in children with sickle cell disease. Pediatr Nephrol. 2010;25(8): 1505-1511.

4. Saraf SL, Zhang $X$, Kanias $T$, et al. Haemoglobinuria is associated with chronic kidney disease and its progression in patients with sickle cell anaemia. Br J Haematol. 2014:164(5):729-739.

5. Guasch A, Navarrete J, Nass K, Zayas CF. Glomerular involvement in adults with sickle cell hemoglobinopathies: Prevalence and clinical correlates of progressive renal failure. J Am Soc Nephrol. 2006;17(8):22282235.

6. Sharpe CC, Thein SL. Sickle cell nephropathy - a practical approach. Br J Haematol. 2011;155(3):287-297.

7. Scheinman JI. Sickle cell disease and the kidney. Nat Clin Pract Nephrol. 2009;5(2): 78-88.

8. Tejani A, Phadke K, Adamson O, et al. Renal lesions in sickle cell nephropathy in children. Nephron. 1985;39(4):352-355.

9. Potoka KP, Gladwin MT. Vasculopathy and pulmonary hypertension in sickle cell disease. Am J Physiol Lung Cell Mol Physiol. 2015:308(4):L314-324.

10. Hand WL, King-Thompson NL. Effect of erythrocyte ingestion on macrophage anti- bacterial function. Infect Immun. 1983; 40(3):917-923.

11. Vinchi F, Costa da Silva M, Ingoglia G, et al. Hemopexin therapy reverts hemeinduced proinflammatory phenotypic switching of macrophages in a mouse model of sickle cell disease. Blood. 2016;127(4):473-486.

12. Belcher JD, Marker PH, Weber JP, Hebbel RP, Vercellotti GM. Activated monocytes in sickle cell disease: potential role in the activation of vascular endothelium and vaso-occlusion. Blood. 2000;96(7):24512459.

13. Klug PP, Kaye N, Jensen WN. Endothelial cell and vascular damage in the sickle cell disorders. Blood Cells. 1982;8(1):175-184.

14. Mahoney DH Jr, Fernbach DJ. Monocyte functions in sickle cell disorders. Am J Pediatr Hematol Oncol. 1983:5(4):409-411.

15. Bhatt AS, Welm A, Farady CJ, et al Coordinate expression and functional profiling identify an extracellular proteolytic signaling pathway. Proc Natl Acad Sci USA. 2007;104(14):5771-5776.

16. Oiu D, Owen K, Gray K, Bass R, Ellis V. Roles and regulation of membrane-associated serine proteases. Biochem Soc Trans. 2007;35(Pt 3):583-587.

17. Rampino T, Soccio G, Gregorini M, et al. Neutralization of macrophage-stimulating protein ameliorates renal injury in anti-thy 1 glomerulonephritis. J Am Soc Nephrol. 2007;18(5):1486-1496

18. Leonard EJ. Biological aspects of macrophage-stimulating protein (MSP) and its receptor. Ciba Found Symp. 1997;212: 183-191.

19. Wang MH, Julian FM, Breathnach R, et al. Macrophage stimulating protein (MSP) binds to its receptor via the MSP beta chain. J Biol Chem. 1997;272(27):16999. 17004.

20. Ryan TM, Ciavatta DJ, Townes TM. Knockout-transgenic mouse model of sickle cell disease. Science. 1997;278(5339): 873-876.

21. Kasztan M, Fox BM, Speed JS, et al. LongTerm Endothelin-A Receptor Antagonism Provides Robust Renal Protection in Humanized Sickle Cell Disease Mice. J Am Soc Nephrol. 2017;28(8):2443-2458.

22. Jerebtsova M, Kumari N, Obuhkov Y, Nekhai S. Adenoviral E4 gene stimulates secretion of pigmental epithelium derived factor (PEDF) that maintains long-term survival of human glomerulus-derived endothelial cells. Mol Cell Proteomics. 2012;11(11):1378-1388.

23. Misra RP. Isolation of glomeruli from mammalian kidneys by graded sieving. Am J Clin Pathol. 1972;58(2):135-139.

24. Savin VJ, Sharma R, Lovell HB, Welling DJ. Measurement of albumin reflection coefficient with isolated rat glomeruli. J Am Soc Nephrol. 1992;3(6):1260-1269.

25. Wang L, Almeida LE, de Souza Batista CM, et al. Cognitive and behavior deficits in sickle cell mice are associated with profound neuropathologic changes in hippocampus and cerebellum. Neurobiol Dis. 2015:85:60-72.

26. Khaibullina A, Almeida LE, Wang L, et al. Rapamycin increases fetal hemoglobin and ameliorates the nociception phenotype in sickle cell mice. Blood Cells Mol Dis. 2015;55(4):363-372.

27. Sporn LA, Marder VJ, Wagner DD. Inducible secretion of large, biologically potent von Willebrand factor multimers. Cell. 1986;46(2):185-190

28. Wagner DD, Bonfanti R. von Willebrand 
A. Khaibullina et al.

factor and the endothelium. Mayo Chin Proc. 1991;66(6):621-627. YC, Harris DC. HIF-1alpha expression follows microvascular loss in advanced murine adriamycin nephrosis. Am J Physio l Renal Physiol. 2005;288(1):F198-206.

30. Blouin MJ, De Paepe ME, Trudel M. Altered hematopoiesis in murine sickle
disease. Blood. 1999:94(4):1451-1459.

31. Kawaguchi $M$, Orikawa $H$, Baba $T$ Fukushima T, Kataoka H. Hepatocyte growth factor activator is a serum activator ulating protein. FEBS J. 2009;276(13):3481 3490.

32. Prasain N, Stevens T. The actin cytoskeleton in endothelial cell phenotypes. Microvasc Res. 2009;77(1):53-63.

33. Wash PK, Peace BE, Waltz SE. Met-related receptor tyrosine kinase Ron in tumor growth and metastasis. Adv Cancer Res. 2008;100:1-33

34. Haymann JP, Stankovic K, Levy P, et al Glomerular hyperfiltration in adult sickle cell anemia: a frequent he 2010;5(5):756-761.

35. Aygun B, Mortier NA, Seltzer MP, Hankins JS, Ware RE. Glomerular hyperfilsickle cell anemia. Pediatr Nephrol. 2011;26(8):1285-1290.

36. Power JS, Cotran RS. Cytokines and endothelial cell biology. Physio Rev.
1990:70(2):427-451.

Parks TP. Intercellular adhesion molecule-1 gene expression in human endothelial cells.
Differential regulation by tumor Differential regulation by tumor necrosis J Biol Chem. 1992;267(17):12030-12035.

38. Coo Q, Harris DC, Wang Y. Macrophages in kidney injury, inflammation, an
sis. Physiology. 2015;30(3):183-194.

39. Hill GS, Delahousse M, Nochy D, Mande C, Bariety J. Proteinuria and tubulointersti2001;60(5):1893-1903

40. Rollino C, Basolo B, Roccatello D, Menegatti E, Piccoli G. Atypical presence of antimyeloperoxidase antibodies in 2 trans-

41. Tomlinson ML, Garcia-Morales C, AbutElmagd M, Wheeler GN. Three matrix metalloproteinases are required in vive for macrophage migration during embryonic development.

42. Darragh MR, Shat AS, Craik CS. MT-SP1 proteolysis and regulation of cell-microenvironment interactions. Front Biosci. 2008;13:528-539.

43. Rampino T, Collesi C, Gregorini M, et al. Macrophage-stimulating protein is produce by tubular cells and activates mean-
gill cells. J Am Soc Nephrol. 2002;13(3): girl cells.

44. Cantaluppi V, Biancone L, Romanazzi GM, et al. Macrophage stimulating protein may promote tubular regeneration after acute injury. J Am Soc Nephrol. 2008;19(10): 1904-1918.

45. Neath KA, Hebbel RP. Sickle cell disease: renal manifestations and mechanisms. Nat Rev Nephrol. 2015;11(3):161-171.

46. Chang K, Yo HP, Wang MH. Activation of RON differentially regulates claudin expression and localization: role of claudin1 in RON-mediated epithelial cell motility.

47. Sultana C, Sher Y, Rattan V, Johnson C, Kalra VK. Interaction of sickle erythrocytes with endothelial cells in the presence of endothelial cell conditioned medium induces oxidant stress leading to Blood. 1998;92(10):3924-3935.

48. Juncos JP, Grange JP, Groat AJ, et al. Early and prominent alterations in hemodynamiss, signaling, and gene expression following renal ischemia in sickle cell disease. Am
J Physiol Renal Physiol. 2010;298(4):F892899.

49. Brenner BM, Lawler EV, Mackenzie HS. The hyperfiltration theory: a paradigm shift in nephology. Kidney Int

1996;49(6):1774-1777.
50. Bieniasz M, Radhakrishnan P, Faham N, De La O JP, Whelm AL. Preclinical Efficacy of Ron Kinase Inhibitors Alone and in
Combination with PI3K Inhibitors for Treatment of sfRon-Expressing Breast Cancer Patient-Derived Xenografts. Chin Cancer Res. 2015;21(24):5588-5600.

798

haematological | 2018; 103(5) 